\title{
Explore the Opportunities and Challenges of Marketing in the Era of Big Data
}

\author{
Zhang Jing \\ School of Economics and Management Xijing University, xi’an, 710123
}

Keywords: big data; opportunity; challenge; marketing

\begin{abstract}
China's economy with the social development and progress has made great leap forward, the continuous upgrading of science and technology plays a very important role in the development. In today's information age, the development of Internet technology has been very mature, has become an integral part of people's lives. With the people's dependence on Internet consumption, the use of big data has been quietly integrated into the various fields of marketing, but also by the widespread concern of enterprises. The arrival of the big data era provides enterprises with more and more valuable information resources. This paper focuses on the opportunities and challenges in the market marketing era of big data, and in search of the road for the enterprise in the era of big data to find more and more valuable resources, enhance the market competitiveness, create a good economic benefits.
\end{abstract}

China entered the twenty-first Century, the rapid economic development, market competition is also increasingly fierce. The popularity of information communication, the wide application of the Internet, for our work, study, entertainment, life brings more convenience to the use of the Internet, we can stay at home can get more information on the United States, McKinsey proposed the concept of "big data". We are in the background of big data, every minute per minute will have a variety of information and data in the form of transmission through the internet. The use of big data in marketing, for the enterprises in the aspects of production efficiency, improve the management of marketing channels, etc., to provide valuable information, and laid a solid foundation for enterprises to enhance market competitiveness.

\section{An overview}

"Big data" refers to the use of a diversified form, collected from various fields of huge data, has the characteristics of real-time. At the technical level, the relationship between big data and cloud computing has an inseparable relationship with the positive and negative poles of the battery. The circulation of data cannot be carried out alone, and a computational framework must be used. Its characteristic is relying on "cloud computing" to obtain and deal with massive information. Alvin Toffler in 1980 "the third wave", "big data" compared to "the third wave of the cadenza". Big data is mainly from the increasingly popular network locks associated with, but also by many departments, enterprises attach great importance to. Big data is not the traditional model of data. In 2011, McKinsey Research Report "massive data: innovation, competition and improve the next generation rate in the new field of" pointed out that the data has penetrated into every field of industries and business functions, and gradually become an important production factor; and people for the use of sea quantity data will also herald the new wave of productivity growth and consumer surplus wave arrival. In this regard, it can be seen that the arrival of the era of big data is an integral part of the era of change. In May 10, 2013, the Alibaba said Ma in Taobao anniversary party, we did not find out when the PC era, mobile Internet has come, did not find out when the mobile Internet, big data era has come [1].

The arrival of big data, will bring great innovation to many enterprises, many fields. But we must soberly realize that the core of big data is to dig the value of data for customers, rather than piling up the hardware and software. Therefore, the application methods of big data in different fields will be the key to the good development of enterprises in the future. At the same time, we also believe that in the context of big data, the future development of enterprises will be more broad. 


\section{Marketing opportunities in the era of big data}

At present, marketing under the background of big data is facing a variety of opportunities, in such an opportunity environment, is very helpful to the growth and development of enterprises, strengthen market competitiveness.

Understand the service needs of customers, is the core of marketing, namely we often say "target marketing", provide the real need of the product and service for the customer, this is bound to be able to establish a good relationship between enterprises and businesses for marketing. In the context of big data, enterprises can use information technology to establish channels of communication with customers, understand customer needs, so as to achieve precision marketing standard, but also can promote products and services in the process of marketing. In marketing, we should pay special attention to the integration of the four aspects of cost, convenience, communication and customer. Only by combining these four organically, can we provide customers with more distinctive services. As our enterprise, the most important thing is to follow "customer is God". All marketing purposes start from customers, consider for customers, and bring economic benefits to enterprises. In the background of big data, the marketing of enterprises is not limited and the traditional mode of marketing, sales. The traditional model of marketing will consume a lot of manpower, material and financial resources, and will also contain most of the energy of the enterprise. In the big data background, the marketing model can save the cost first, and the counterpart production reduces the waste on the product. Secondly, the reduction in manpower and physics has reduced the waste of widely publicized resources. The new sales model, also can let customers feel the experience of high quality and inexpensive; in the context of large data, people shopping more convenient, customers at home using the Internet can be completed in your product and service needs; finally, in the field of communication, customers buy products in the network, the enterprise can real-time communicate with customers, so that customers more comprehensive understanding of product information, but also established a good long-term platform for communication with customers[2].

The so-called portfolio sales refers to the customer in the process of consumption, not only to meet the individual consumer products, but to further tap the potential spending power, and further to expand sales, to meet customer consumption standard. Nowadays, the combination marketing method has been widely used by enterprises, and achieved good results. Many enterprises will carry out statistical analysis and Research on the sales data by product sales, to study consumer demand, finally realize the combination optimization on the products, to meet the consumer at the same time, to improve the economic efficiency of enterprises. For example: in the cake industry, many people would love to eat cakes and pastries, the prices of most can let customers accept, through data analysis, can detailed analysis of peripheral consumer spending and consumer preferences, consumer preferences and consumption ability and introduce more attractive products, thus ensuring its consumption the product can be more popular with our clients, but also can promote the consumption, for businesses to bring more and better economic benefits, enhance the sales amount[3].

\section{The challenge of marketing in the era of big data}

There are two sides to a thing, enterprise ushered in opportunities also will face more challenges, especially in the context of large data, we see many conveniences which brings to us at the same time, we should also take into account the problems and difficulties of big data bring to us. Big data can bring more information resources for us, but we can clearly understand that not all information is correct, there are a lot of information is wrong, there may even mislead the enterprise, causes the enterprise to cause unnecessary losses. Therefore, how to make better use of big data has become an urgent problem for our enterprises to solve. Only by ensuring the authenticity and accuracy of information can we provide reference value for enterprises.

With the integration of big data in life, the market environment has become increasingly complex, many of the previous precision marketing information because of lack of identification, 
analysis of the conditions are not accurate. In order to enlarge the sale of products, the enterprise transfers the product information to the customers without the determination of their customers, expands the publicity of the products, and causes the users to be tired and troubled. Nowadays, we often see a lot of information that has nothing to do with ourselves in our communication information, which we collectively call "junk information"'". Enterprises to expand their propaganda regardless of whether the customer needs to publicize, if things go on like this will let customers have, disgust and psychological resistance, which is not up to the expected corporate publicity, there may bring negative effects to the enterprise's reputation, must not countervail.

In the past, the traditional mode of marketing, mostly to customer visits, telephone communication and other ways. The arrival of big data, the use of data analysis to obtain a new way of customer demand, gradually replaced the traditional marketing model application. But the use of big data marketing methods, must grasp the data analysis and processing capabilities, which on the current marketing personnel put forward higher requirements. Enterprises want to use this resource, it must be aimed at the existing marketing personnel to enhance the ability and training, this period requires enterprise calls a lot of energy and money to strengthen staff learning promotion. At the same time, enterprises should employ high-tech talents in related fields, and improve the related equipment and facilities, which will undoubtedly increase the cost of enterprises [4].

With the continuous improvement of the level of science and technology, and the continuous maturity of network technology, some criminals carry out illegal activities according to the information on the network. In everyday life we occasionally will receive some telephone fraud and fraud information, and the other is to understand the information on their own, these are a lot of information in our online shopping, or the transmission out. Criminals will use these acquired information to conduct fraud against us. Therefore, in the context of big data, how to correctly use information and protect information is not leaked, and it is imperative to do a good job of inter secret security work. Many customers in order to better protect their own information is not leaked and change their way of consumption, which will make our marketing more difficult, very detrimental to the marketing activities.

\section{Marketing measures in the era of big data}

The use of big data, enterprises must establish a sound marketing program, do a good job in all aspects of marketing, in order to ensure that enterprise marketing has been fully sublimated and enhanced.

The data is not accurate, is the root of our analysis and treatment is not accurate, so we must proceed in the root, should first strengthen the marketing personnel's data analysis and processing ability, only the strong ability of data processing so that we can get in big data in information resources becomes more accurate, only in this way can the enterprise in marketing correct understanding and understanding of customer needs, and the enterprise should do. In terms of publicity, not blindly publicity, it will cause the customer have tired of the feeling of resistance method, reasonable use of publicity, is particularly important, both to save costs, reduce unnecessary waste, but also can improve the efficiency of publicity. For example: advertising on the media, do some special publicity, to participate in some of the low cost of process programs and so on, can achieve propaganda enterprise products, enhance the visibility of enterprises purposes [5].

The arrival of the big data era, the traditional mode of marketing concept, has been far from meeting the needs of enterprise production, sales and customer consumption, services. This requires our traditional mode of marketing reform, innovation, the introduction of new technologies and means, the only way to let our enterprises in the production and marketing, to meet customer demand standards. The cost of enterprises in the above concerns is that we need to consider the new technology needs more and more personnel ability excellent technology, which requires our business in terms of learning staff efforts, increase the cost, and the need to recruit more talents. In this regard, suggestions to the enterprises with their own requirements, reasonable cost, according to their own marketing industry scale, and the scope of marketing, make accurate positioning, avoid the investment cost is far greater than the benefits of the situation. In the use of big data today, 
many enterprises have been affordable, but also accurate positioning of their own position, to ensure its own benign development. The development of the more prominent, such as: Alibaba group's Taobao, Jingdong mall, etc., have achieved great success.

The promotion of scientific and technological level represents the rapid development of China's economy. Nowadays, in the tide of information age, enterprises must strengthen confidentiality consciousness while doing marketing work well. How to keep the information secret is a problem we must solve now. Many companies are aware of this problem, but do not know how to solve it. In fact, the key to solve this problem is to find out from itself, first of all, in the information, perhaps, employees should do a good job of information storage, not abuse. It also prohibits the use of customer information to seek illegitimate interests. Secondly, in the process of information transmission, to do encryption work, so as to further ensure that customer information is not stolen, in order to further achieve the purpose of protecting customer information. Finally, we should do a good job of confidentiality education work for internal staff, so that employees understand the importance of confidentiality, as well as information leakage caused harm to customers and enterprises, but also bring unnecessary trouble to themselves. Only in many aspects, meticulous meticulous secrecy work, can bring more space for the development of enterprises, for the enterprise to bring the customer's high praise [6].

\section{Concluding remarks}

Big data era has arrived, he could bring more information in production and marketing, in the data acquisition and processing, enterprises should conscientiously do a good job of more detailed analysis, acquisition, so that marketers can more comprehensive understanding of customer needs, which can be more comprehensive to provide customers with better and more distinctive the comprehensive services, increase customer satisfaction and customer loyalty. At the same time in obtaining information confidential, as far as possible to protect the enterprise and the customer information will not be leaked or stolen, which to some extent increase the difficulty of marketing, but the marketing effect will be obviously.

In short, the advent of big data, is our enterprise facing opportunities, but also a new challenge, only the difficulties, solve all the problems on the road ahead, to occupy a space for one person in the future market competition.

\section{References}

[1] Wang Feng. The opportunities and challenges of marketing in the big data era, [J]. national circulation economy, 2017, (19), 5-6.

[2] Zheng Hao, Li Ruyan, Liu Yuxuan. Marketing opportunities and challenges in the era of big data [J]. South agricultural machinery, 2017,48 (05), 124+128.

[3] Lichy J, Kachour M, Khvatova T. Big Data is watching YOU: opportunities and challenges from the perspective of young adult consumers in Russia[J]. Journal of Marketing Management, 2017.

[4] Zhang P, Cui Q, Hou Y, et al. Opportunities and challenges of wireless networks in the era of mobile big data[J]. Chinese Science Bulletin, 2015, 60(5-6):433.

[5] Xinning S U. Opportunities and Challenges Faced by Digital Libraries in the Era of Big Data[J]. Journal of Library Science in China, 2015.

[6] Huang H, Cao Z, Feng C. Opportunities and challenges of big data intelligence analysis[J]. Caai Transactions on Intelligent Systems, 2016. 